\title{
TROPICALIDADE E INTENCIONALIDADE EM LIVROS DIDÁTICOS DE GEOGRAFIA: UMA LEITURA DAS OBRAS DE AROLDO DE AZEVEDO, ELIAN ALABI LUCCI E MELHEM ADAS
}

\section{Tropicality and intentionality in geography textbooks: a reading of the works by Aroldo de Azevedo, Elian Alabi Lucci and Melhem Adas}

\author{
Bruno Falararo de Mello \\ Doutor em Organização do Espaço pela UNESP \\ brunofmello@yahoo.com.br \\ João Pedro Pezzato \\ Professor Adjunto da UNESP, campus de Rio Claro \\ joaopezzato@hotmail.com
}

Artigo enviado para publicação em 07/07/2020 e aceito em 11/10/2020

DOI: $10.12957 /$ tamoios.2020.52514

\section{Resumo}

Este trabalho é fruto de pesquisa que relaciona o currículo de Geografia, em especial os conteúdos da climatologia escolar em livros didáticos do Ensino Médio, com as ciências de referência. Para tanto, foram selecionados autores de livros didáticos representativos da Geografia escolar brasileira entre as décadas de 1960 e 2010, com o objetivo de proceder a uma leitura crítica acerca dos conteúdos de climatologia veiculados em suas obras didáticas. $\mathrm{Na}$ perspectiva metodológica do paradigma indiciário, este artigo trata, especificamente, de divulgar as análises a respeito da tropicalidade brasileira evidenciada sob a óptica de três autores nacionais - Aroldo de Azevedo, Elian Alabi Lucci e Melhem Adas -, cujos discursos evidenciam seus alinhamentos. Foi possível observar que o tema é objeto de destaque nos três livros didáticos e que as ideias que sustentam as posições de Aroldo e Elian sobre o clima tropical são semelhantes. Ambos apontam que o clima tropical é essencialmente danoso ao desenvolvimento nacional. Contudo, Melhem Adas adota posição oposta aos demais autores.

Palavras-chave: Climatologia escolar; Intencionalidade; Livro didático; Tropicalidade.

\begin{abstract}
This paper is the result of research that links the Geography curriculum, especially the contents of school climatology in high school textbooks, with the reference sciences. To this end, authors of didactic books representative of Brazilian school geography between the 1960s and 2010 were selected, with the objective of proceeding with a critical reading about the climatology contents conveyed in their didactic works. In the methodological perspective of the indicial paradigm, this paper deals specifically with disseminating the analyzes regarding Brazilian tropicality evidenced from the perspective of three national authors Aroldo de Azevedo, Elian Alabi Lucci and Melhem Adas -, whose speeches show their alignments. It was possible to observe that the theme is highlighted in the three textbooks and that the ideas that support Aroldo and Elian's positions on the tropical climate are similar. Both point out that the tropical climate is essentially harmful to national development. However, Melhem Adas takes the opposite position to the other authors.
\end{abstract}

Keywords: School climatology; Intentionality; Textbook; Tropicality. 


\section{Introdução}

É fato praticamente inconteste que vasta parte do território brasileiro tem por característica, no tocante ao clima, a tropicalidade. É essa tropicalidade que deu o tom da nossa colonização, favorecendo a exploração de madeira nativa e o cultivo de produtos tropicais para serem comercializados na Europa, cujo clima mais frio sempre foi impeditivo a determinadas culturas agrícolas. Além disso, a tropicalidade esteve durante muito tempo vinculada a características negativas do território brasileiro, como insalubridade, indolência e aspereza.

No decurso de nossa pesquisa, que teve por foco a análise da climatologia veiculada na cultura escolar por meio de livros didáticos em série temporal (1967-2013), deparamos com narrativas que apresentam concepções conflitantes acerca da tropicalidade brasileira. Ora as médias de temperatura não exibem os "excessos" de outras áreas tropicais do mundo, ora elas são atenuadas quase que milagrosamente por ação do relevo, ora à tropicalidade subjaz um discurso escamoteador que historicamente embasou a exploração do Brasil.

Por tratar-se de pesquisa documental e temporal, selecionamos obras de autores de grande vendagem de livros didáticos que perpassam as tendências da Geografia, em uma perspectiva diacrônica. Nossa intenção foi investigar como os conteúdos da climatologia foram abordados ao longo do tempo. Os livros didáticos escolhidos foram O Mundo em que Vivemos (1967, $5^{\mathrm{a}}$ edição) e Terra brasileira (1968, 41 $1^{\mathrm{a}}$ edição), de Aroldo de Azevedo; Geografia Geral (1986, 4ª edição), de Elian Alabi Lucci; Panorama geográfico do Brasil (1985, $2^{\mathrm{a}}$ edição), de Melhem Adas; Geografia: contextos e redes (2013, v. 1, $1^{\text {a }}$ edição), de Ângela Corrêa da Silva, Nelson Bacic Olic e Ruy Lozano. Neste artigo, especificamente, apresentamos excertos de três obras, que abordam a tropicalidade brasileira sob diferentes perspectivas: Terra brasileira, Geografia Geral e Panorama geográfico do Brasil.

Além de evidenciar a questão da tropicalidade em determinados livros didáticos desses autores, procuramos destacar as possíveis intencionalidades no tratamento que eles dão a esse tema. A esse tocante, servimo-nos do paradigma indiciário, método de investigação de tipo hermenêutico, oriundo da História, cuja fundamentação se baseia na interpretação de sinais, símbolos, indícios e demais elementos conjuntivos, visando à construção do sentido do objeto investigado (GINZBURG, 2016).

Em linhas gerais, os fundamentos desse paradigma remetem à publicação de relatos de crítica proferidas pelo médico e especialista de arte italiano Giovanni Morelli entre 1874 e 1876, cuja técnica investigativa de atenção aos detalhes e pormenores de obras artísticas consagradas rendeu-lhe, à sua época, a distinção precisa de obras de arte originais e copiadas, levando à reorganização de exposições em vários museus da Europa.

O livro didático é considerado "obra complexa", dadas as suas características de produto editorial em constante atualização técnica, de ser apontado como veículo de transmissão ideológica e, entre outras propriedades, de ter grande influência na configuração da cultura escolar. Ele é um veículo de destaque, pois, em grande parte, influencia a seleção de conteúdos que ocorrem no cotidiano escolar das redes públicas e privadas de ensino. Nesse sentido, a investigação proposta tem por objetivo tecer uma narrativa com a finalidade de produzir uma leitura da climatologia escolar em livros didáticos de grande circulação em diferentes décadas do país.

Para isso, o currículo foi tomado como objeto cultural que representa uma dimensão da cultura escolar na medida em que a escola produz uma cultura original que perpassa a cultura social mais ampla, como apontam Chervel (1990) e Goodson (1997). 


\section{A tropicalidade é um problema?}

De acordo com Sant'Anna Neto (2015, p. 18-22), a primeira classificação climática do Brasil foi elaborada por Henrique Morize, em 1889, que partiu do reconhecimento de zonas térmicas do globo, acrescentando alguns fatores geográficos como altitude, maritimidade e latitude. Engenheiro de formação, Morize dedicou-se à Geografia, e por muitos anos dirigiu o Observatório Nacional, tendo lecionado Física e Meteorologia na Escola Politécnica do Rio de Janeiro. Em 1922, ele elaborou sua segunda classificação climática para o Brasil, desta vez munido de mais dados meteorológicos e incorporando alguns princípios da classificação climática da proposta de Wladimir Köppen.

Em sua primeira classificação climática, Morize classificava os climas brasileiros em três grupos: equatorial, subtropical e temperado, com base nas isotermas superiores a $25^{\circ} \mathrm{C}$, de $20^{\circ} \mathrm{C}$ a $25^{\circ} \mathrm{C}$ e inferior a $20^{\circ} \mathrm{C}$, respectivamente. Ele considerava toda a região compreendida entre as isotermas de $20^{\circ} \mathrm{C}$ a $25^{\circ} \mathrm{C}$ - que abrangia a então Região Norte, de Pernambuco até a Bahia, e a Região Sul, da Bahia até São Paulo - como pertencente ao clima subtropical, entendendo-se o termo subtropical como paliativo a um clima tropical associado a toda fonte de males. Obviamente, trata-se de um enquadramento muito forçado; a maior do Brasil, por essa proposta, se beneficiaria de um clima mais ameno do que ocorria na realidade. Foi uma manobra de Morize para mitigar a tropicalidade, tentando demonstrar que o Brasil tinha potencial para receber imigrantes europeus e se desenvolver economicamente, já que o nosso clima não diferiria muito do da Europa meridional. Na classificação de 1922, Morize abandonou o termo "subtropical" e adotou "tropical" para as atuais regiões Nordeste e Centro-Oeste, cujas temperaturas médias anuais abrangiam a faixa entre $20{ }^{\circ} \mathrm{C}$ e $25^{\circ} \mathrm{C}$.

O professor Carlos Miguel Delgado de Carvalho também deu importante contribuição às primeiras tentativas de classificar os climas brasileiros. Ele procurou adotar uma abordagem mais geográfica para a sua classificação de 1917, levando em conta não apenas as médias, mas também a circulação atmosférica (SANT'ANNA NETO, 2015, p. 11). Sob influência de Paul Vidal de la Blache, de Jean Brunhes e especialmente de Emmanuel de Martonne, Delgado de Carvalho propôs uma classificação climática que considerava as influências dos climas tropicais no desenvolvimento econômico e na adaptação do homem. Nas palavras de Sant'Anna Neto (2015, p. 12), “[...] ao contrário de Henrique Morize, não se deixou influenciar pelo determinismo climático e assumiu uma postura possibilista, tal qual era o pensamento dominante na Geografia francesa desta época." . Depreende-se que para Delgado de Carvalho a tropicalidade não era um problema de primeira ordem, mas apenas uma questão de ajuste dos homens a ela. Sua classificação de 1917, apesar de aparentemente similar à de Morize de 1889, foi bastante conflitante quantos aos limites entre os climas tropicais, subtropicais e temperados (SANT'ANNA NETO, 2015, p. 11).

Ainda nos primórdios das classificações climáticas do Brasil, Afrânio Peixoto, médico sanitarista e professor da Faculdade de Medicina do Rio de Janeiro, foi um dos defensores do mundo tropical face aos preconceitos dos detratores desse ambiente, para os quais havia uma natural inferioridade dos povos das zonas tórridas. Sua primeira classificação climática, divulgada em 1908, levava em conta aspectos relacionados à saúde e ao bem-estar do homem. Apesar de considerar três tipos climáticos principais para o Brasil (equatorial, tropical e temperado), tal qual Morize e Delgado de Carvalho, Peixoto enfatizava a tropicalidade do nosso território, que para ele era algo positivo (SANT'ANNA NETO, 2015, p. 16-18). 
Para Sant'Anna Neto (2015, p. 18), as principais diferenças entre as classificações de Morize, Delgado de Carvalho e Peixoto estão relacionadas "muito mais à questão da delimitação da zona tropical do que aos elementos geográficos e meteorológicos considerados na proposta de distribuição espacial dos climas". A delimitação da zona tropical e a adjetivação da tropicalidade foram, assim, objeto de divergência entre os primeiros cientistas brasileiros. Veremos que essas visões conflitantes também estiveram presentes na cultura escolar, veiculadas nos livros didáticos de Geografia.

\title{
A Tropicalidade em Aroldo de Azevedo
}

No livro didático Terra brasileira, de 1968, Aroldo de Azevedo se dedica ao tratamento de questões concernentes ao Brasil, dividindo-as em três partes: natureza, população e economia. O capítulo dedicado ao estudo dos climas brasileiros é chamado "país tropical". Aroldo assume, já no título e depois, no corpo do texto, que a característica marcante do país é a tropicalidade, conforme demostra a página 41, contida na Figura 1. Todavia, um fato chama a atenção: a adjetivação que ele dá à nossa tropicalidade.

Assumir a tropicalidade é assumir uma singularidade e uma característica particular que merece maior atenção, pois é um dos traços que dá uma identidade comum à nação brasileira. Todavia, trata-se de uma tropicalidade diferenciada:

\begin{abstract}
As temperaturas - No Brasil, as temperaturas médias são em geral elevadas, em consequência de nossa posição geográfica. Mas não apresentam os excessos conhecidos noutras áreas tropicais. As mais altas não passam de $28^{\circ}$, que é a média anual do Sertão do Nordeste. As mais baixas registram-se no Planalto Meridional e não descem a menos de $17^{\circ}$. Dois são os principais fatores que influem sôbre as temperaturas: a latitude e o relêvo (grifo nosso, p. 41).
\end{abstract}

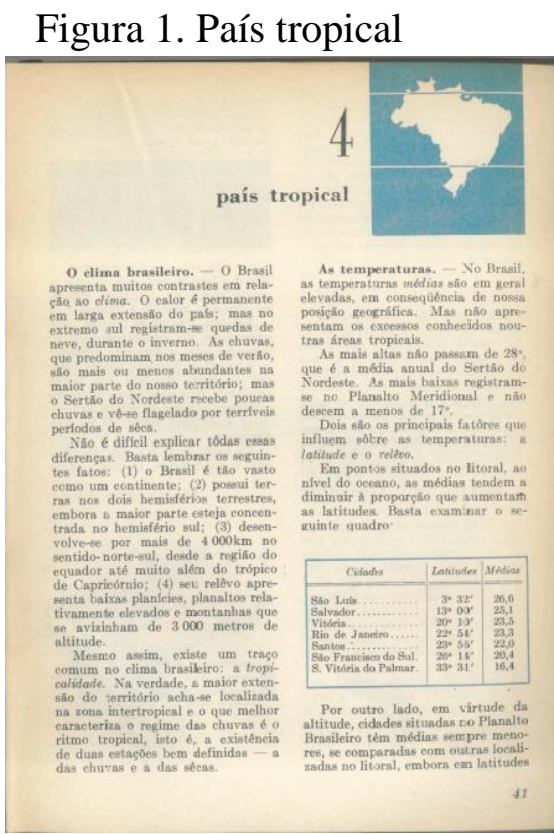

Fonte: AZEVEDO, Aroldo de. Terra brasileira. 41ª edição. São Paulo: Companhia Editora Nacional, 1968.

O trecho em destaque é indicativo do preconceito de Aroldo com o clima tropical. O que poderíamos chamar de "excessos", em se tratando de temperaturas em áreas tropicais, e por que a tropicalidade seria, ela mesma, um problema a ser mitigado? Para 
esse argumento ter alguma validade, o autor deveria ter contraposto as médias de outras áreas tropicais, para efeito de comparação. Mesmo se assim o fizesse, ainda seria passível de críticas; não se vê razão para acreditar que a tropicalidade se constitua em problema ou algo a ser suavizado, quer pela latitude, quer pela influência do relevo, quer por outro fator a ser alegado.

Destacamos esse excerto porque nos parece muito indicativo da maneira de pensar do autor: se o clima tropical brasileiro não apresenta excessos em razão de alguns fatores específicos, mormente o relevo, significa afirmar, então, que o clima tropical, em si, é um problema; assumir que nosso clima tropical é mitigado equivale a nos aproximar das nações desenvolvidas que gozam de clima temperado, bem como a nos afastar daquelas subdesenvolvidas, de clima tropical, com os excessos - e atrasos - que ele acarreta.

A respeito dos discursos de Aroldo sobre a tropicalidade e a geopolítica, Santos (1984, p. 50) enfatiza:

Para Aroldo de Azevedo, há tanto vantagens como desvantagens em relação à imensidade do espaço geográfico brasileiro. Há que assumir a nossa tropicalidade, que apresenta inúmeras vantagens, a par com a considerável proporção de população branca que possuímos e a nossa excepcional posição geopolítica. O Brasil ainda é muito jovem e sofre os resultados de uma crise de crescimento, não tendo ainda se posicionado quanto aos fins políticoeconômicos. Para o futuro, contamos com prováveis áreas de dominação: Bacia Amazônica, Bacia Platina, costa africana e Bolívia. O Brasil tem, também, todas as condições para "crescer por dentro", ou seja, contém em si mesmo um verdadeiro império colonial.

O clima está inserido no rol das vantagens de Aroldo, como bem expressa Santos. A imensidão do território, beneficiado por um tipo de clima semelhante em sua maior parte - a lhe conferir certa homogeneidade natural -, de estações chuvosas bem definidas e livre dos "excessos" de outras áreas tropicais, favoreceriam o Brasil a tornar-se o país do futuro. Todavia, segundo Santos (1984, p. 51), ao discurso ufanista de Aroldo subjaz uma contradição flagrante:

Toda essa argumentação de Aroldo de Azevedo parece conter uma contradição fundamental. $\mathrm{Na}$ aparência, o discurso tenta se posicionar contrariamente às concepções geopolíticas de raízes ratzelianas. Também, aparentemente, enaltece a escola francesa com seus contornos positivistas e os seus ideais de liberalismo político. Mas, na essência, o seu pensamento permanece preso ao conteúdo daquela geopolítica ao defender uma política imperialista para o Brasil com base em seus ensinamentos [de Ratzel]. Todavia, uma melhor reflexão pode indicar a coerência dessa mensagem dadas as origens de classe do autor, herdeiro dos quadros oligárquicos pré-30. Os grupos sociais que detiveram essas características e que ainda predominavam na intelectualidade da época sempre mantiveram, sob a capa dos ideais liberais e positivistas, um pensar elitista/autoritário, portanto, antiliberal e carregado de uma mentalidade colonialista para com os povos considerados inferiores e sujeitos à dominação. Inclusive o caráter racista é uma constante em seus discursos.

Um possível eco da mentalidade colonialista para com os povos considerados inferiores e sujeitos à dominação é a tropicalidade, que Aroldo assume, mas com as devidas mitigações. Ser tropical equivale a ser dominado, a ser inferior, a ser colonizado por quem detém o poder e os meios para explorar outrem. Se estar no meio tropical equivale a estar sob o domínio do atraso e da exploração, e não sendo absolutamente possível aos homens alterar o tipo de clima ao qual estão submetidos, a melhor maneira é mascarar a tropicalidade, ou, antes, torná-la algo diferençável das demais tropicalidades 
$\overline{\text { mundo afora: eis a ausência dos excessos. É o caso em que o clima se torna subordinado }}$ a uma ideologia.

\section{A Tropicalidade em Elian Alabi Lucci}

Elian Alabi Lucci é um autor de livros didáticos de Geografia que chegou a ser liderança de vendas no início da década de 1980 (RESENDE, 1986). O livro que analisamos, Geografia geral, é, como define seu autor logo no prefácio ao estudante, um compêndio que objetiva tratar sobre a paisagem geográfica e a atuação do homem no meio ambiente. No capítulo que dedica aos estudos do clima, Elian parte das teorias gerais da climatologia para depois chegar aos climas do Brasil. Não diferindo muito de Aroldo de Azevedo, o autor trata a tropicalidade como um problema.

Conforme exposto em um quadro intitulado "Saiba que...", constante na Figura 2, Elian aborda a questão da tropicalidade, adotando o mesmo tom pejorativo que há no livro Terra brasileira:

\footnotetext{
Saiba que...

No Brasil, as médias não são excessivas; as máximas não ultrapassam os 28 ${ }^{\circ} \mathrm{C}$ (sertão nordestino), e as mínimas não descem além de $17{ }^{\circ} \mathrm{C}$ (planalto Meridional). O relevo brasileiro, apesar de suas modestas altitudes, influi sobre as condições climáticas de grande parcela do nosso território, corrigindo os exageros de sua tropicalidade (grifo nosso, p. 75).
}

Sem entrarmos no mérito da utilidade dos quadros da série "Saiba que...", que aparecem em todos os capítulos da obra didática, principiamos a análise pela primeira sentença: no Brasil, as médias não são excessivas. Elian claramente fere um dos princípios da Geografia tradicional que ele mesmo evoca no primeiro capítulo do livro Geografia geral: a analogia. As médias não são excessivas em relação a qual outro ponto da Terra? Solta, a sentença não tem validade; apenas em comparação a outro local fica possível afirmar que as médias térmicas são ou não são excessivas. Isso suscita, ainda, um segundo ponto de debate: a relatividade do excesso. A média máxima de $28{ }^{\circ} \mathrm{C}$ pode ser um excesso para quem habita uma área de clima frio. Do mesmo modo, a média mínima de $17^{\circ} \mathrm{C}$ pode ser um excesso para quem está habituado aos calores das regiões quentes.

Figura 2. Os exageros da tropicalidade em Elian Alabi Lucci

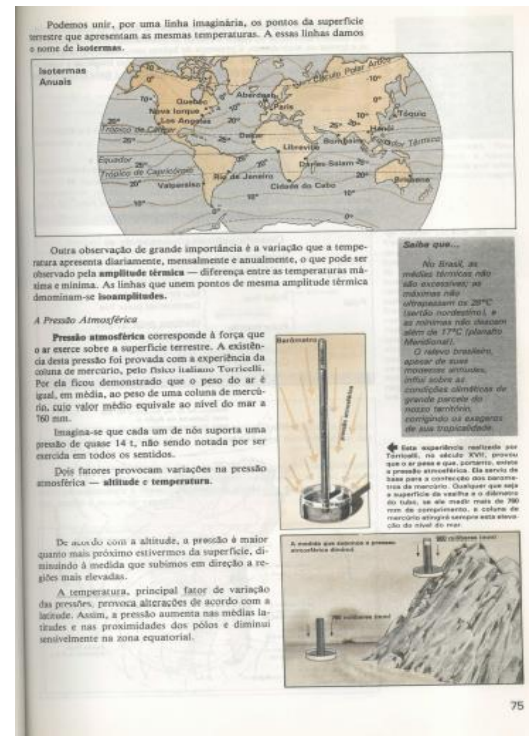

Fonte: LUCCI, Elian Alabi. Geografia geral: $2^{\circ}$ grau. $4^{\text {a }}$ ed. São Paulo: Saraiva, 1986. 
A sentença "corrigindo os exageros de sua tropicalidade" é a mais emblemática do quadro-informe. Parece ter havido certo pendor entre os geógrafos brasileiros mais antigos e alinhados à Geografia tradicional em encarar a tropicalidade como um problema a ser superado ${ }^{1}$. Aroldo de Azevedo pensava assim e o expressava sem pudores. Por sua fala, Elian se denuncia e mostra seguir a mesma linha de pensamento. Ora - perguntamonos - o que pode haver de tão nocivo em climas tropicais a ponto de geógrafos quererem mascará-lo em suas obras?

Talvez - e isso é apenas uma hipótese que aventamos - a associação ruim com os climas tropicais seja oriunda da ideia colonialista de exploração das vastas áreas tropicais e subjugação dos povos considerados atrasados e passíveis de domesticação, uma ideia cujo eco localizamos nas obras de Aroldo. O clima tropical seria, do ponto de vista de um colonizador europeu, naturalmente insalubre, propício a tornar os homens indolentes, dada a insolação intensa. O Brasil, sendo um país tropical por excelência, não poderia escapar a esse estereótipo. Qual a solução que os autores (Aroldo e Elian) encontram, não podendo mudar esse quadro natural? Mascarar a realidade. Se o clima não pode ser mudado por nossa vontade, mudamos então a forma de classificar o clima.

A ideia de uma tropicalidade exagerada que precisa ser corrigida, nem que o seja à força de alguma classificação arbitrária, como a de Henrique Morize de 1889, é, assim, antiga e arraigada. Não nos surpreende, portanto, que ainda encontrasse espaço em livros didáticos nos anos 1970, como no de Elian. Em seu juízo, a tropicalidade característica do Brasil, intrinsecamente danosa, é corrigida - quase que por milagre - pelo relevo, ainda que as altitudes sejam modestas. Pela essa lógica, se nossa altitude fosse mais protuberante, seríamos como a Suíça dos trópicos.

A abordagem de Elian ao tema da tropicalidade brasileira apresenta características semelhantes daquela observada nos estudos de Hervé Théry (2014), quando analisa o tratamento dos países tropicais nos livros didáticos franceses de Geografia entre 1925 e 1960. Para Théry, a organização dos livros segue estritamente as determinações dadas pelos textos oficiais e os conteúdos são fortemente influenciados pelo estado da sociedade: neste período, os países tropicais eram principalmente colônias a mais a serem exploradas.

Com pesquisa também centrada em livros didáticos do ensino médio, o trabalho de Théry mostra que houve pouca influência das pesquisas acadêmicas nos conteúdos dos livros publicados entre 1925 e 1960. O autor observa, assim, que os trabalhos dos geógrafos acadêmicos do período perceberam a originalidade dos processos morfogenéticos e pedogenéticos sob clima tropical e equatorial e, entretanto, tal impressão não foi refletida nos livros didáticos (2014, p. 163). Como conclusão, o autor observa:

Procurando a tropicalidade, encontramos nos livros didáticos uma geografia colonial, influenciada por currículos igualmente marcados pela história colonial. Pela insistência sobre as colônias francesas, a ênfase sobre os recursos exportáveis - incluindo neles o trabalho dos indígenas - pela defesa da aventura colonial, esses livros, com raras exceções, têm ajudado a justificar a expansão francesa nos territórios ultramarinos. (THERY, 2014, p. 173).

Com tais referências, permitimo-nos certa observação: parece-nos que a ideia impressa em publicações de Elian a respeito de uma tropicalidade no Brasil, em livros datados de 1970, é, no mínimo, anacrônica. 


\section{A Tropicalidade em Melhem Adas}

Melhem Adas foi um dos autores dos anos 1980 que trouxe as discussões da vertente crítica da Geografia aos livros didáticos. Como destaca Goodson (1997) a respeito da relação entre estabilidade e mudança nos currículos, apesar de estruturas do modelo antigo ainda restarem, isto é, a tradição subsistir, mesmo diante das inovações, novas propostas são inseridas. Desse modo, embora sua obra Panorama geográfico do Brasil, de 1985, não seja exatamente original em relação às obras de Aroldo de Azevedo e Elian Alabi Lucci do ponto de vista da articulação dos temas - a tradicional divisão natureza-sociedade-economia, de aspiração marcadamente lablachiana, ainda persiste -, ele é bastante original quanto ao tratamento da tropicalidade.

No texto para leitura e discussão ao final do capítulo, Melhem Adas propõe, em consonância com sua orientação crítica como método de análise, uma nova interpretação do significado que subjaz à noção de tropicalidade. Se em Aroldo e em Elian vemos uma tentativa de camuflar essa tropicalidade, vista apenas sob o ponto de vista físico, com implicações na saúde dos homens e, consequentemente, na produção econômica, Melhem a vê por um ângulo diferente: o social.

O texto para leitura e discussão é extenso e por isso não vamos transcrevê-lo. Ele aparece integralmente na Figura 3. Destacaremos alguns trechos em que o autor esclarece a razão de o clima tropical haver sido associado a atraso, doenças e pouco propício ao desenvolvimento de atividades semelhantes às existentes nos países desenvolvidos de clima temperado.

Figura 3. O significado da tropicalidade em Melhem Adas

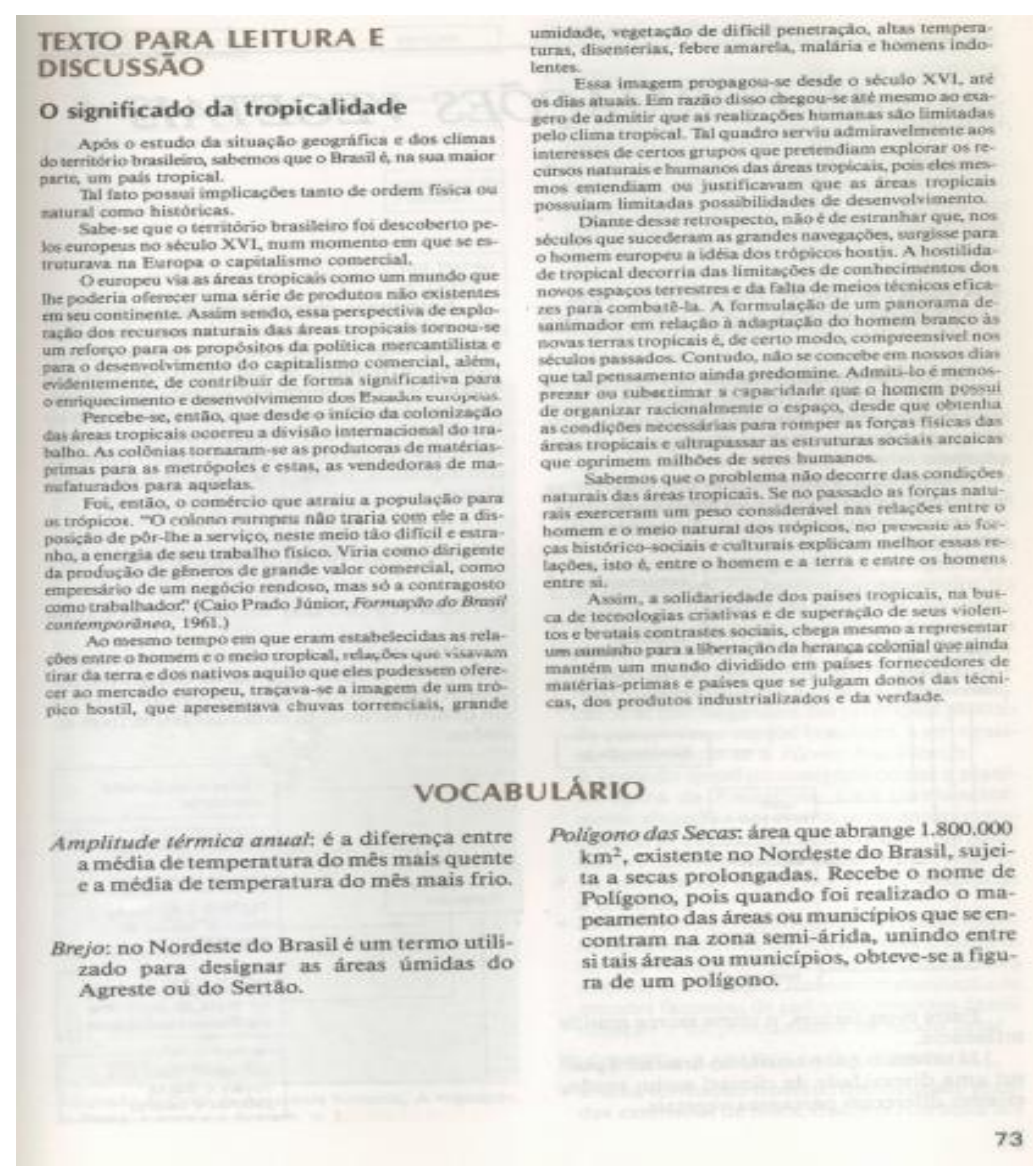

Fonte: ADAS, Melhem. Panorama geográfico do Brasil: aspectos físicos, humanos e econômicos. $2^{\mathrm{a}}$ ed. revista e ampliada. São Paulo: Editora Moderna, 1985. 
Ao expor que o europeu via as áreas tropicais como um novo mundo de oportunidades e, consequentemente, de exploração, a oferecer produtos não existentes em seu continente, Melhem argumenta que aí nasceu a nefasta visão de inferioridade que se arrastou pelos séculos afora. A tropicalidade, então, passou a ser associada a lugares destinados somente à satisfação das necessidades econômicas da metrópole. Os povos nativos foram considerados indolentes e inferiores; a terra, em geral, considerada hostil, chuvosa, úmida, quente, de vegetação densa e quase impenetrável, repleta de doenças como desinteria, febre amarela, malária, entre outras. Não à toa que os primeiros climatologistas do Brasil, a exemplo de Henrique Morize, não mediram esforços para mitigar, quando não obliterar, os elementos característicos do clima tropical.

Para Melhem, a má imagem que desfrutavam as áreas tropicais não apenas é infundada, mas propositadamente criada:

Essa imagem propagou-se desde o século XVI até os dias atuais. Em razão disso chegou-se até mesmo ao exagero de admitir que as realizações humanas são limitadas pelo clima tropical. Tal quadro serviu admiravelmente aos interesses de certos grupos que pretendiam explorar os recursos naturais e humanos das áreas tropicais, pois eles mesmos entendiam ou justificavam que as áreas tropicais possuíam limitadas possibilidades de desenvolvimento (p. 73).

É especificamente nesse trecho que, à luz do paradigma indiciário, torna-se bastante claro o significado que a tropicalidade assumia e que o autor quer expressar: exploração, em todos os sentidos. Após apontar a causa do problema da tropicalidade - 0 interesse de certos grupos na espoliação das riquezas do mundo tropical -, ele indica possíveis saídas para a promoção do desenvolvimento desses países:

Sabemos que o problema não decorre das condições naturais das áreas tropicais. Se no passado as forças naturais exerceram um peso considerável nas relações entre o homem e o meio natural dos trópicos, no presente as forças histórico-sociais e culturais explicam melhor essas relações, isto é, entre o homem e a terra e entre os homens entre si.

Assim, a solidariedade dos países tropicais, na busca de tecnologias criativas e de superação de seus violentos e brutais contrastes sociais, chega mesmo a representar um caminho para libertação da herança colonial que ainda mantém um mundo dividido em países fornecedores de matérias-primas e países que se julgam donos das técnicas, dos produtos industrializados e da verdade.

Afirmando que o problema nunca decorreu das condições naturais das áreas tropicais, ou seja, que o clima não é, em si, o fator do atraso, o autor assume outro sentido à tropicalidade. Ser tropical não é ser ruim. Não há juízo de valor a ser atribuído ao clima. A natureza é o que ela é. O sentido da tropicalidade, assim, deve ser o da solidariedade a permear a relação entre os países que outrora padeceram do mesmo infortúnio, compartilhando tecnologias, intercambiando soluções para os contrastes sociais - herança do colonialismo - e estabelecendo caminhos para a libertação da pobreza e da miséria.

\section{Considerações Finais}

A tropicalidade brasileira é objeto de destaque nos livros didáticos de Aroldo de Azevedo, Elian Alabi Lucci e Melhem Adas, embora cada qual à sua maneira. Todos eles se reportam à tropicalidade como fator distintivo do Brasil e de sua posição no mundo. 
Para Aroldo, a tropicalidade brasileira é absolutamente singular e assume o papel de unidade natural do povo brasileiro; para Elian, a tropicalidade brasileira, em um primeiro momento encarada como excessiva, ora apresentando uma visão anacrônica, ora empregando eufemismos, é corrigida quase que milagrosamente pelo relevo; para Melhem, a tropicalidade escamoteia um discurso historicamente construído para exploração e opressão.

As ideias que sustentam as posições de Aroldo e Elian sobre o clima tropical são claramente desfavoráveis à aceitação da tropicalidade in natura, bruta; o clima tropical é visto como essencialmente danoso, estando ligado a um discurso historicamente construído de atraso. Se ser tropical é ruim, e não sendo possível mudar a posição geográfica do Brasil no mundo, a melhor maneira de modelar esse discurso é maquiando a tropicalidade, seja por meio da ideia de médias não excessivas, seja em função de um relevo que corrige providencialmente os seus exageros. Resolve-se, assim, um incômodo problema, passando ao aluno a falsa noção de que a tropicalidade é ruim, mas que o Brasil, por alguma razão especial, foi agraciado com a mitigação dos excessos ou dos exageros.

Melhem Adas adota o tom oposto. Assumindo a vertente crítica da Geografia, não se conforma com o discurso da justificação do atraso por meio da tropicalidade. Parte, assim, a desmistificá-lo: o clima tropical, antes de qualquer adjetivação, foi usado como argumento para manter os povos coloniais sob o jugo de suas metrópoles. Uma vez convencidos da "natural" inferioridade que o clima lhes impôs, esses povos não teriam outra alternativa a não ser curvar-se aos interesses de seus exploradores, mais avançados em termos tecnológicos e civilizacionais por serem oriundos de climas mais clementes e favoráveis ao homem. Na contramão de Aroldo e Elian, Melhem advoga a solidariedade entre as nações tropicais - ex-colônias europeias -, e encerra o capítulo do clima com uma mensagem de esperança, pontuando o que busca com a sua Geografia: a transformação da realidade.

Tendo servido, assim, a variados interesses ao longo da História, a tropicalidade brasileira tem sido associada a diferentes discursos - às vezes antagônicos -, que atendem a determinadas demandas e refletem o pensamento e o alinhamento dos difusores do conhecimento geográfico.

\section{Notas}

1 - Embora Sant'Anna Neto faça menção às chamadas escolas determinista e possibilista, destacamos que essa divisão não é ponto pacífico no pensamento geográfico. A respeito, sugerimos a consulta às seguintes fontes: CARVALHO JUNIOR, Ilton Jardim de e MORAES SOBRINHO, Aparecido Pires. A perpetuação de mitos no pensamento geográfico: a ideia das influências ambientais e a falsa dicotomia determinismo/possibilismo. Revista da Associação Nacional de Pós-Graduação e Pesquisa em Geografia (Anpege), v. 13, n. 22, set./dez. 2017, p. 164-197; SANTOS, Milton. Por uma Geografia Nova: Da crítica da Geografia a uma Geografia crítica. 6 ed. São Paulo: EDUSP, 2004.

2 - Sant'Anna Neto (2015, p. 8-9) faz especial menção à influência que o pensamento do geógrafo norteamericano Ellsworth Huntington teve sobre os meios acadêmicos da Europa, dos Estados Unidos e mesmo do Brasil até meados do século XX. Em sua obra Civilization and climate, de 1915, esse autor sustentava que o mundo tropical não favorecia o desenvolvimento econômico e que o homem do mundo temperado era naturalmente superior.

\section{Referências}

ADAS, Melhem. Panorama geográfico do Brasil: aspectos físicos, humanos e econômicos. $2^{\mathrm{a}}$ ed. revista e ampliada. São Paulo: Editora Moderna, 1985.

AZEVEDO, Aroldo de. Terra brasileira. 41 a edição. São Paulo: Companhia Editora Nacional, 1968. 
$\overline{\text { CAPEL, Horace. Filosofía y ciencia en la geografía contemporánea. Barcelona: Bacanova }}$ Temas Universitarios, 1981.

CHERVEL, André. L'histoire des disciplines scolaires. Réflexions sur un domaine de recherche. Histoire de l'éducation, n. 38, p. 59-119, 1988.

GINZBURG, Carlo. Mitos, emblemas, sinais: morfologia e história. Tradução de Federico Carotti. $2^{\mathrm{a}}$ ed. $7^{\mathrm{a}}$ impressão. São Paulo: Companhia das Letras, 2016.

GOODSON, Ivor. A construção social do currículo. Tradução de Maria João Carvalho. Lisboa: EDUCA, 1997.

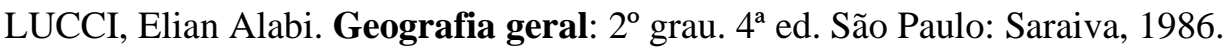

RESENDE, Márcia Spyer. A Geografia do aluno trabalhador: caminhos para uma prática de ensino. São Paulo: Edições Loyola, 1986.

SANT'ANNA NETO, João Lima. As matrizes da construção da Climatologia Geográfica brasileira. In: MONTEIRO, Carlos Augusto de Figueiredo (org.). A construção da climatologia geográfica no Brasil. Campinas: Editora Alínea, 2015.

SANTOS, Wilson dos. A obra de Aroldo de Azevedo - uma avaliação. 1984. 98 f. Dissertação (Mestrado em Geografia) - Instituto de Geociências e Ciências Exatas, Universidade Estadual Paulista, Rio Claro.

THÉRY, H. Os países tropicais nos livros didáticos de Geografia do ensino secundário francês entre 1925 e 1960. Revista Brasileira de Educação em Geografia, v. 4, p. 160-174, 2014. 